\title{
ESTIMULAÇÃO PRECOCE DA CRIANÇA - EXPANSÃO DO PAPEL DO ENFERMEIRO PSIQUIÁTRICO
}

\author{
Maria de Nazaré de Oliveira Fraga* \\ Raimunda Nobre Damasceno** \\ Violante Augusta Batista Braga*** \\ Rita Maria de Oliveira Forte****
}

\begin{abstract}
RESUMO - As autoras relatam a implantação de um programa de estimulação precoce desenvolvido pela mãe no próprio domićlio com a supenvisão periódica do enfermeiro. As autoras qualificam a experiência como algo gratificante e promissor pois assegura novo campo de atuação para os enfermeiros psiquiátricos.
\end{abstract}

\begin{abstract}
The authoress relate the implantation of a program of permature stimulation developed for mother in her own domicile with the periodic superintendence of nurse. The authoress qualify the experience as something gratifier and promising because it gets a new fiel of work for psychiatric nurses.
\end{abstract}

\section{INTRODUÇÃO}

A assistência psiquiátrica no Brasil. tal como a assistência à saúde geral, se dá fundamentalmente pela execução de açōes de caráter curativo. Nesse contexto, a atuação do enfermeiro psiquiátrico ainda está concentrada fundamentalmente dentro dos hospitais. Mesmo em hospitais psiquiátricos com atendimento ambulatorial ou em serviços previdenciários de assistência psiquiátrica ambulatorial, a atuação do enfermeiro tem se caracterizado pelo empirísmo e falta de sistematização que em quase nada tem contribuído no sentido de marcar a presença do profissional junto à clentela ali assistida.

As consequências da situação se fazem presentes, tanto a nível assistencial quanto de ensino, pela pobre inovação da prática de enfermagem no setor e também pela escassez de experiências de aprendizagem voltadas à saúde mental que vêm sendo oferecidas aos alunos de enfermagem ao longo do tempo.

O desempenho do enfermeiro em hospitais psiquiátricos convencionais é pouco compensador e até mesmo frustrante. Alr, seu papel é ambivalente pois ao mesmo tempo que se propõe a uma atuação terapêutica, na verdade, também, é executor das medidas restritivas e limitadoras tão comuns aquele ambiente. A busca de alternativas assistenciais mais voltadas à promoção da saúde mental da clientela $\mathrm{e}$ possibilitadoras de maior autonomia do enfermeiro psiquiátrico, são, portanto, objetivos prioritários neste momento. Tais alternativas são viáveis prin- cipalmente em hospitais não-psiquiátricos e mesmo junto a grupos vulneráveis no próporio domiçlio.

Este trabalho relata uma experiência em andamento que possibilita a ampliação do papel do enfermeiro psiquiátrico em particular e também dos enfermeiros em geral. Documenta-se a implantação de um programa de estimulação precoce de crianças co-executado pelo enfermeiro e mães primíparas que se inícia na maternidade e prossegue com visitas domiciliares periódicas até quando as crianças completam 12 meses de idade.

\section{FUNDAMENTAÇĀO TEÓRICA}

A influência exercida pelos individuos e pelo ambiente sobre o desenvolvimento físico e psicologico das crianças constitui hoje um campo de interesse e de estudos por parte de pesquisadores de diferentes áreas (AINSWORTH. 1962; BOWLBY, 1951; BOWLBY, 1982; GESELL et alii, 1977; LINDHOLM, 1984; MUSSEN et alii, 1977; OLIVEIRAA et alii 1985).

A mudança brusca de ambiente pela qual passa o bebê, em virtude do nascimento, coloca-o em situação de desamparo e vazio, situação esta que deve ser amenizada por atitudes de solicitude e aconchego. Tais atitudes, inicialmente, são atendidas de forma instintiva pela mãe, embora nem sempre haja compreensão da amplitude de significado que as mesmas têm para o desenvolvimento global da criança.

\footnotetext{
* Enfermeira Mestre em Enfermagem Psiquiátrica. Professora Adjunta da Universidade Federal do Ceará Autora.

* Enfermeira, cursando Mestrado em Psicologia Social, Professor Assistente da Universidade Federal do Ceará. Co-Autora.

*** Enfermeira, Especialista em Enfermagem Assistencial, Professor Auxiliar de ensino da Universidade Federal do Ceará, co-Aútora.

**** Aluna do Curso de Enfermagem da Universidade Federal do Ceará, Monitora da Disciplina Enf ermagem Psiquiátrica. Co-Autora.
} 
Os cuidados físicos relacionados à higiene, aquecimento, faldas secas, posição confortável e alimentação suprem necessidades que vão além de proporcionar nutrição e conforto. Eles são elementos essenciais para o desenvolvimento sadio da personalidade do bebê. $O$ atendimento pronto aos apelos do bebê leva-o a confiar ao mundo e livrar-se da tensão dolorosa causada pela fome e outros desconfortos. $\mathrm{O}$ retardo ou falta de atendimento geram desconfiança e acúmulo de tensảo levando-o a ser irritadiçõ e inseguro (MUSSEN, et alii, 1977).

No início, o recém-nascido não tem percepção clara de sua existência independente do mundo èvice-versa. O que há são rudimentos de percepçao representados pelas sensações ' de dentro' relacionada à fome e "de fora" rélacionada ào que pode ou não atender à fome e outros desconfortos.

LEBOYER (1986) diz ser necessário alimentar a pele, tanto quanțo o ventre do bebê, ou seja alimentar o "de fora" com o mesmo cuidado que o "de dentro".

Tecnicamente, alimentar o "de fora" e o "de dentro" do bebê vem sendo chamado de estimulação cỏm qualificativos como sensorial, precoce, entre outros. Dia a dia a estimulação ganha terreno como facilitadora do desenvolvimento físico, intelectual e psicológico nos primeiros cinco anos de vida da criança, como terapêutica para casos de prematuros e desnutridos e como prevenção propriamente dita da saúde mental.

É certo que a herança genética determina padrões e limites de conduta, entretanto, é certo também que $o$ indivíduo detém potencialidades que se estimuladas na forma e momentos corretos possibilitam grandes variações de alcance (MUSSEN et alii, 1977; OLIVEIRA, et alii, 1985).

Os bebês necessitam de estimulos especificos para alcances especificos. Eles precisam de estimulação visual correspondente a variações como luz $x$ sombra, de estimulação tátil e cinestésica e de variaçōes no nível e nos tipos de sons que os cercam. Os estímulos em diferentes áreas - visual, tátil, sonora - favorecem a percepção positiva que a criança começa a ter do mundo. A proximidade freqüente do rosto da mãe em seu campo visual lhe dá a impressão de como as coisas se dispōem no espaço; o diálogo carinhoso da mãe ajuda-a a desenvolver a própria vocalização; o uso precoce das mãos ajuda-a a explorar e sentir mais os objetos, a tocar, puxar, apanhar (MUSSEN et alii, 1977; OLIVEIRA et alii, 1985).

"Ser levados, embalados, acariciados, pegos, massageados constitui para os bebê, alimentos tão indispensáveis, senão mais, do que vicaminas, sais minerais e proténas. Se for privada disso tudo e do cheiro, do calor e da voz que ela conhece bem, mesmo cheia de leite, a criança vai-se deixar morrer de fome"'. Esta citação de LEBOYER (1986) ilustra muito bem o alcance dos benefícios que podem ser obtidos com a estimulação e também os prejuízos físicos e psicológicos que podem advir de sua ausência.

À medida que o bebê é cuidado, mudado, carregado e movimentado por uma mãe amorosa, ele recebe muitos estímulos de que verdadeiramente necessita. Crianças subnutridas, se acaraiciadas ao serem alimentadas, tem maior ganho de peso que aquelas que não recebem tal estímulo. Os ef eitos positivos também são evidentes em prematuros de baixo peso que aumentam rapidamente de peso desde que as mães sejam solícitas e demonstrem preocupação e habilidade no atendimento de suas necessidades físicas e emocionais. (KAUS \& KENNELL.1986; MUSSEN et alii,1977).

Estudos sobre as possíveis causas de distútbios psiquiátricos indicaram que a ausência de oportunidade para estabelecer laços afetivos ou então as prolongadas ou repetidas separações entre indivíduos são antecedentes de grande significado na história das pessoas que apresentam os referidos distúrbios. (AINSWORTH; 1962; BOWLBY; 1951).

Mães doentes, incapazes de responder aos filhos ou inibidas por regulamentos hospitalares ou por normas pré-concebidas estão menos aptas a reduzir a tensão e promover relaxamento dos bebês. Por outro lado, estando atenta às reações do bebê aos seus estrmulos, cada mãe pode aprender quais deles (música, aconchego, embalo, etc.) sāo mais eficientes para acalmá-lo. Essa aprendizagem vai deixá-la mais tranquila em relação à sua função materna e ao seu auto-conceito de "boa-mãe" (MUSSEN et alii, 1977). Essa percepção não está satisfatoriamente desenvolvida em todas as mães. A idade, o número de filhos, a condiçōes socio-econômicas entre outros, são fatores que exercem grande influência sobre a habilidade, equilíbrio e motivação das mães no cuidado das crianças.

A estimulação compreende o uso de técnicas e atitudes adequadas e indispensáveis à criança nos primeiros meses de vida para garantir uma evolução tão normal quanto possível. Estimular não significa forçar a criança, significa acompanhá-la e desenvolver sua máxima potencialidade. Fazer a criança se desenvolver dá alegria e confiança aos pais (OLIVEIRA et alii, 1985).

Visando o desenvolvimento global da criança, a estimulação deve compreender o uso de medidas, atitudes e técnicas voltadas a diferentes áreas. GESELL et alii (1977), divide as manifestações de conduta do indivíduo em quatro áreas: conduta motora, conduta adaptativa, conduta de linguagem e conduta pessoal-social. A conduta motora engloba a capacidade de realizar movimentos como equilibrar a cabeça, sentar, ficar de pe e andar. A conduta adaptativa compreende a adaptação de criança a objetos e tarefas propostos que depende do desenvolvimento motor, de sua inteligência e capacidade construtiva. A conduta de linguagem inclui toda forma de comunicação visível, audível incluindo 
vocalizações, movimentos posturais e imitiação e compreensão do que dizem os adultos. A conduta pessoal-social compreende a reação frente a outras pessoas e frente a estŕmulos culturais. Para cada uma dessas áreas e em diferentes faixas de idade o autor indica objetivos a serem atingidos como estimulação e os procedimentos que devem ser executados para atingf-los. Em nosso trabalho adotamos o esquema proposto por GESELL et alii (1977), que será apresentado na próxima seção deste trabalho.

$\mathrm{Na}$ execução de um programa de estimulação numa perspectiva de trabalho de saúde mental é preciso ter bem presente que $o$ atendimento deve estar voltado a, pelo menos, duas pessoas - a mãe e a criança. A assistência deve ser alargada no sentido de atender as necessidades da māe e com isso deixá-la mais apta e liberada para o envolvimento com a criança.

Para iniciar qualquer programa de estimulação, institucionalizado ou não, é necessário um treinamento da equipe responsável pelo mesmo. Para sensibilização quanto ao trabalho a ser realizado, para abertura em aprender com a clientela, para o respeito aos valores culturais da mesma e para adaptar as orientações às dúvidas e demandas das mães. Sobre isso PERCY (1979) diz que há mães perfeitamente capazes de criar ambiente af etuoso e confortável, no qual a criança vai crescendo com problemas mínimos de ajustamento e que em tais casos o que se deve fazer é observar atentamente e aprender com elas.

A interação com pessoas adultas é uma fonte bastante rica em experiência necessárias a um crescimento intelectual e uma responsividade social ótima. Uma consequência importante da interação inicial do bebê com a mãe ou outra pessoa que cuida dele e da experiência prazerosa dar resultante é que as respostas de aproximação dadas por eles, generalizar-se-ão a outros indivíduos. Isso indica a importância da execução de um programa de estimulação da criança executado pela própria mãe, sendo a mesma assessorada e assistida por técnicos capacitados e com formação voltada para à área de saúde mental. Um programa nesses moldes, caracteriza-se como uma atividade de saúde mental por excelência.

Qualquer assistência prestada no domicúlio não pode perder de vista a compreensão das relações que permeiam os membros da famflia, assim como as características psicológicas dos mesmos. A mãe se mostrará mais relaxada, menos stressada e mais envolvida como papel que deve desempenhar se forem trabalhados os fatores determinantes de conflitos, inseguranças e stress. $O$ enfermeiro especialista em psiquiatria, por excelência, está preparado para tal. Por outro lado, os enfermeiros da área materno-infantil, com motivação para este trabalho, poderão ser sensibilizados e tecnicamente preparados para o tipo de intervenção que ora se propõe.

\section{DESCRIÇÃO DA EXPERIÊNCIA}

A disponibilidade da mãe, o aconchego que acontece durante a amamentação, o conversar afetuoso, são elementos que propiciam a relação sadia mãe-filho. Vários autores, como foi referido anteriormente, destacam a importância do estabelecimento precoce desse relaciomento e da sua manutenção, sem interrupções, como forma de lançar os alicerces da segurança emocional da criança e de sua capacidade para enfrentar choques e frustrações, tão comuns à vida de todos os indivíduos.

O trabalho de estimulação aqui descrito tem como população-alvo as mães primíparas e seus filhos. A escolha recai sobre esse grupo por razōes que estão presentes na própria literatura especializada. Estudo feito por LINDHOLM (1984), com um grupo de mães primíparas mostrou que as mesmas tinham preocupações e desejavam ter mais conhecimentos sobre aspectos relacionados à estimulação dos filhos. Quanto a isso elas manifestaram interesse sobre: a) brinquedos - idade para introdução, tipos adequados à idade e sexo, explicações sobre preferências de certos brinquedos; b) idade para a criança ser estimulada a vestir-se sozinha, ir à escola, usar troninho, andar, falar, dormir sozinha; c) estimulação - o que é, meios, locais adequados para estimulação, a importância e finalidade. Estes dados indicam que as primíparas estão e constituir um grupo de eleição para um programa de estimulação precoce da criança pois são bastante carentes de conhecimentos e informações específicas.

Na opinião de PERCY (1979), a primípara é mais insegura e para ela estão indicados programas específicos para torná-la mais capaz, menos stressada e mais equilibrada na relação com o bebê. Se a continuidade da aproximação física é promovida, assentam-se as bases para uma aproximação psicológica e para um satisfatório relacionamento mãe-filho.

A experiência de vivenciar a maternidade pela primeira vez pode ser muito ansiogênica para as mulheres. As primíparas, pela ausência de vivências anteriores, não têm parâmetros de comportamento a direcioná-las em relação a que atitudes adotar no cuidado com a criança. Acresce-se a essa limitação, o desconforto físico do puerperio, as dificuldades iniciais com a amamentação ao seio, cuidados com o coto umbilical, que geram insegurança e, de alguma forma limitam seu papel de mãe. Uma outra razão para a realização do trabalho é por acreditar-se que o nascimento do primeiro filho favorece o envolvimento do pai no seu cuidado, assim como o envolvimento de outras pessoas do núcleo familiar mais amplo, com os avós.

A grande meta do programa é estimular e reforçar o relacionamento mãe-filho pela demonstração de 
atitudes e procedimentos simplificados e indispensaveis, visando um envolvimento saudável e consequentemente o máximo desenvolvimento físico da criança e emocional de ambos. Em termos específicos, são metas principais: reforçar as iniciativas e atitudes de aconchego e afetividade da mãe e familiares com a criança; reforçar a adoção do aleitamento materno como fator de socialização da criança; assessorar a mãe no processo de estimulação, contribuindo para o desenvolvimento das máximas potencialidades da criança; promover a saúde mental da mãe e da criança como resultado do envolvimento mútuo, da auto-aceitação da mãe em seu novo papel e da sensação de segurança que passa a ser experimentada pela criança; formar hábitos e atitudes nos familiares quanto ao cuidado com as futuras crianças.

O programa tem como executores os docentes da disciplina Enfermagem Psiquiátrica, dois alunos-bolsistas preparados para tal, a enfermeira lotada no alojamento conjunto da maternidade e, ainda, as mães e familiares. $O$ desenvolvimento do programa se estende até os 12 meses de idade da criança e se processa em duas fases de execução que se subdividem e são analisadas e descritas a seguir:

\section{FASE - Atendimento na Maternidade.}

É prestada assistência ao binômio mãe-filho durante a permanência na maternidade. São realizadas as orientaçōes indispensáveis e que se relacionam ao cuidado geral do bebê, banho, cuidado com o coto umbilical, amamentação, cuidado e higiene do períneo.

Nesse primeiro momento $e$ feito o cadastramento da mãe e filho no programa após as explicações sobre como o mesmo será realizado e é aprazada a primeira visita domiciliar para o perfodo entre 10 e 15 dias após o parto. O cadastramento se dá tendo como critérios: criança nascida de parto normal, a termo; residência nos bairros circunvizinhos à maternidade; aceitação da mãe em participar do programa. Sabe-se que na clientela assistida na maternidade existem grupos de crianças, como os prematuros, que também necessitam, talvez mais, de um programa de estimulação precoce. A opção inicial pela assistência às crianças normais e residentes na circunvizinhança, dá-se, fundamentalmente, pelo reduzido número de pessoas disponíveis para a execução do programa.

Havendo atendimento aos critérios acima, solicita-se que no dia da visita, a mãe tenha uma ou mais das seguintes sucatas caseiras: caixas de fósforos vazias, tampas de deposito de margarina, gravuras coloridas, revistas usadas, linha de costura, copinhos de iogurte vazios. Essa foi a maneira que se encontrou para dividir a responsabilidade do trabalho com a mãe desde o princípio.

2. FASE - Atendimento no Domić́lio Através de visitas.
Em torno do $10^{\circ}$ ao $15^{\circ}$ dia de vida da criança realiza-se a primeira visita domiciliar. Procede-se a uma entrevista pormenorizada para determinar as condições da mãe e do filho, caracterização da família e do domicnlio com vistas à identificação das necessidades e dificuldades sentidas. Com relação ao domicnlio, além dos aspectos relacionados à higiene e saneamento básico, busca-se caracterizá-lo quanto a aspectos prioritários no trabalho de estimulação, como iluminação, ventilação, sons etc. $\mathrm{Na}$ ocasião são feitas orientações específicas a partir dos dados colhidos e das dificuldades referidas e reforçam-se as inciativas e atitudes corretas que vem sendo tomadas pela mãe e familiares.

Segundo o esquema de GESELL et alii (1977), de 0 a 1 mês estão indicados procedimentos de estimulação destinados ao desenvolvimento de reflexos básicos, com ênfase sobre o desenvolvimento do campo visual, auditivo, olfativo e tátil. Com base nesse esquema, entrega-se um roteiro que contém tếcnicas e procedimentos simplificados de estimulação a serem aplicados até a criança completar 1 mês (vide anexo 1). Em seguida, faz-se a leitura do roteiro com demonstração dos principais procedimentos para o período.

Durante a mesma visita procede-se à confecção artesanal de mobiles, chocalhos, aproveitando a sucata que a própria mãe selecionou. Correspondente aos principais procedimentos contidos no roteiro escrito, entrega-se um Guia de Estimulação Ilustrado e Simplificado (vide anexo 2). A razão do uso desse recurso adicional é que muitas das mães que estão sendo acompanhadas têm apenas o 1. grau incompleto ou são analfabetas e uma instrução ilustrada serve de maior estímulo e de ajuda.

A realização da primeira visita entre o $10^{\circ}$ e o 15. dia após o nascimento da criança é estratégica, por várias razões; durante sua permanência na maternidade, a mãe está sujeita a um ambiente estranho, vivenciando uma experiência muito recente, fatores que não liberam sua atenção para orientaçōes e procedimentos mais aprofundados; entre seu $10^{\circ}$ e $15^{\circ}$ dia de puerpério e de cuidado da criança, ela já detém muitas horas de vivências agradáveis e desagradáveis que motivarão a expressar dúvidas, sof rimento e planos imediatos à maneira correta de pegar o bebé, de fazer sua higiene, ainda permanecem desconfortos físicos ou se manifestam problemas relacionados aos seios ou à aparente insaciedade do bebÉ, fatores estes que a motivam a introduzir precocemente a alimentação artificial ou mesmo proceder ao desmame; é importante, ainda nessa fase inicial, envolver o pai e familiares no cuidado da criança.

Quando a criança completa um mês realiza-se a segunda visita, a qual, no geral, segue os mesmos procedimentos da primeira. O que difere são os conteúdos do roteiro e do Guia, os procedimentos ali sugeridos e a demonstração prática dos mesmos. A 
instruções contidas nos dois instrumentos e demonstradas deverão ser executadas até quando a criança completar 3 meses e seguem de GESELL et alii (1977), que indica para o período: conduta motora - liberar movimentos e fortificar músculos das costas e nuca; conduta adaptativa - exercitar musculatura fina, despertar atenção para o mundo que cerca a criança diferenciar odores e tonificar músculos abdominais; conduta de linguagem - tomar consciência dos sons e produzir sons diferenciados e modulados; conduta pessoal-social - continuar o desensolvimento da atenção da criança a tomá-la mais sociável.

Uma terceira, uma quarta e uma quinta visita são realizadas. Isso se dá quando a criança completar respectivamente 3,6 e 9 meses de idade. Os procedimentos gerais de cada visita são semelhantes e em cada uma delas são demonstradas as técnicas a serem executadas até a data da próxima visita. A orientação básica continua sendo a de GESELL et alii (1977) ou seja:

De 3 a 6 meses estão indicados procedimentos que objetivam: conduta motora - fortificar músculos das costas e nuca e preparar a criança para a posição sentada; conduta adaptativa - desenvolver a preensão e capacidade de manipulação para tomar conhecimento das diferentes formas, aperfeiçoar a capacidade de atenção; conduta de linguagem - continuar o desenvolvimento da atenção direcionando-a à percepção de sons distintos e vindos de diferentes direções; conduta pessoal-social - desenvolver independência e adquirir a noção de permanência do objeto.

De 6 a 9 meses estão indicados procedimentos: conduta motora - desenvolver a musculatura dorsal e preparar para engatinhar; conduta adaptativa - fortalecer músculos da boca e preparar-se para os novos estágios no processo de alimentação, desenvolver percepção de cores; conduta de linguagem - relacionar o som com a figura que o origina, pronunciar sons simples; conduta pessoal-social - tornar-se mais independente e sociável, desenvolver noção de permanência do objeto.

De 9 a 12 meses os procedimentos visam: área motora - desenvolver os músculos da perna e sentir os pés como ponto de apoio; conduta adaptativa desenvolver habilidades com ambas as mãos para alcançar e manusear objetos; conduta de linguagem - imitar sons e desenvolver vocabulários, incentivar 0 gosto pela música; conduta pessoal-social atingir maior independência e sociabilidade, desenvolver o hábito de cortesia e de ordem.

Lamenta-se a impossibilidade de incluir os demais roteiros e Guias Ilustrados, uma vez que torna-se necessário atender às normas que estipula apenas 20 páginas para cada trabalho.

Está programada uma última visita a ser realizada quando a criança completa 12 meses. Na oca- sião deve-se proceder à avaliação do crescimento e desenvolvimento da criança, sua conduta nas quatro áreas definidas por GESELL et alii (1977), e, conseqüentemente, chegar-se à avaliaçãoa global do programa de estimulação precoce.

É importante proceder-se a uma apreciação de trabalho, embora superficial, uma vez que as primeiras crianças acompanhadas ainda não completaram 12 meses, idade definida para a avaliação.

Em princípio, a receptividade das mães ao trabalho proposto é muito boa. Vale destacar que a idéia de realizá-lo no domicllio proporcionou oportunidade para grande aprendizagem e descoberta de certos valores da clientela. Começa-se a perceber que um número significativo de mães procede ao desmame por volta da época em que a criança completa um mês de nascida, número também significativo de mães não retorna à maternidade para a revisão do parto. Observa-se em relação a essas duas decisōes um fato bastante curioso: se as orientações dos técnicos sobre amamentação e retorno para revisão coincidem com a opinião do marido, sogra e vizinhas facilmente elas serão seguidas. Se há divergência de opiniōes geralmente as orientações adotadas pelas mães são as dos familiares ou da vizinhança. PERCY (1979), reporta-se ao tema afirmando que os avós mantêm-se pouco próximo do casal nos primeiros anos ou meses do casamento. Entretanto, quando chega um bebê eles entram em cena podendo ajudar bastante ou gerar conflitos. A segunda possibilidade ocorre quando existem conflitos nos hábitos de cuidar, alimentar e educar o bebê. Quando há discordância entre as orientações do técnico de saúde e as da avo, facilmente esta é a vencedora.

Os dois fatos exemplificados acima mostram que as orientações e conselhos que se processam no âmbito de um consultório, longe da realidade social da clientela, facilmente estão fadadas ao insucesso.

A avaliação do programa de estimulação precoce e das crianças que estão sendo acompanhadas deverá ocorrer quando as mesmas estiveram com 12 meses de idade. Esta, certamente, é uma limitação à descrição dos resultados no presente momento. Entretanto, é possível dizer que, no geral, a aceitação por parte das mães é boa, especialmente por parte daquelas que contam com uma situação socio-econômica mais estável.

De uma forma não muito exata, observa-se que a maioria das crianças vem se desenvolvendo bem. As crianças que têm apresentado problemas de saúde, são aquelas filhas de mães muito pobres, e que residem em casas que não têm as minimas condições de higiene, ventilação ou conforto.

No momento da visita domiciliar ocorrem situações que estão a indicar, em princípio, o aperfeiçoamento e ampliação do envolvimento de familiares e dos vizinhos mais próximos do binômio mãe-filho. Eles verdadeiramente compartilham o dia a dia da mãe e exercem influência sobre sua maneira 
de cuidar da criança e sobre as decisões que ela toma. Em razão disso é necessário uma troca maior entre técnicos e eles para possibilitar a minimização das divergências na forma de cuidar das crianças e de assessorar as mães.

\section{CONCLUSÃO}

Um número muito reduzido de enfermeiros estão trabalhando com estimulação precoce de crianças e encarrando a atividade como um campo de atuação da enfermagem. Os enfermeiro psiquiátricos, em sua esmagadora maioria, estão lotados em hospitais psiquiátricos realizando atividades convencionais e pouco gratificantes. A experiência aqui descrita, autoriza a apontar o surgimento de um novo campo de atuação para a categoria de enfermagem, especialmente para o enfermeiro psiquiátrico e da área materno-infantil.

O campo da estimulação precoce também não está sendo ocupado satisfatoriamente por outros grupos profissionais. A modalidade do trabalho aqui apresentado, embora se inicie em uma instituição, caracteriza-se perfeitamente como uma atividade independente do enfermeiro, com autonomia completa de atuação.

Em grandes cidades, com uma clientela economicamente favorecida e bem conscientizada quanto à importância da prevenção em saúde, é perfeitamente viável o desenvolvimento remunerado do trabalho e fora do âmbito do domićllio. Nessa perspectiva, uma clínica pré-natal e de puericultura privada dirigida por enfermeiros com filosofia psicoprofilática pode associar a opção ideal de acompanhamento das crianças até 12 meses de idade, prestando assistência geral e também específica no âmbito da estimulação precoce. Para um trabalho nesses moldes, compreendendo assistência pré-natal com enfoque psicoprofilático e assistência da criança via estimulação precoce como ação de saúde mental, é saudável adotar o mínimo corporativismo possível. Dessa forma, considera-se que, idealmente, deve-se ter enfermeiro que são ao mesmo tempo especialistas em enfermagem materno-infantil e em enfermagem psiquiátrica e de saúde mental ou, como segunda alternativa, tambem ideal, o trabalho em equipe de enfermeiros da área materno-infantil com enfermeiros psiquiátricos e de saúde mental.

\section{REFERÊNCIAS BIBLIOGRÁFICAS}

1 AINSWORTH. M.D.S. The effects of matemal deprivation: revien of findings and contraversy in context of research strategy. WHO. (Public Health Papers, n.. 14) Genebra, 1962.

2 BOWLBY, J. Matemal, care and mental health, World Health Organisation, (Monograph Series, no. 2.) Genebra, 1951. $194 \mathrm{p}$.

3 - Formação, e rompimento dos laços afetivos. São Paulo, Martins Fontes, 1982.

4 FERNANDES. J.D.A. Enf ermagem no contexto da saúde mental, Revista Baiana de Enfermagem, Salvador, 1:7-23, 1981 .

5 FRAGA, M.N.O. et alii. Prática de Enfermagem nas regiōes norte e nordeste. In: CONGRESSO BRASILEIRO DE ENFERMAGEM, Recife, 1985. Anais... Brasília, 1985.

6 FRAGA, M.N.O. et alii. Influência das percepções, observações no atendimento ao paciente psiquiátrico, Revista Brasileira de Enfermagem, Brasília, 33 (2): 223-35, 1980.

7 GESELL, A. et alii. Psicologia evolutiva de 1 a 16 anos, Buenos Aires, Paidós. 1977.

8 KAUS, M. \& KENNELL, J.G. La relacion madre-hijo. Buenos Aires, Editorial Médica Panamericana, 1986.

9 LEBOYER, R. Shantala: Uma arte tradicional, São Paulo, GROUD, 1986.

10 LINDHOLM. R.R. Cuidado do lactente no primeiro ano de vida - conhecimentos desejados por um grupo de mães, Revista Brasileira de Enfermagem, Brasília, 37 (I): 36$-43,1984$.

11 MUSSEN, P.G. et alii. Desenvolvimento e personalidade da Criança. 4 ed., São Paulo, harper e Dow do Brasil, 1977.

12 OLIVEIRA, I.C.S. et alii. Programa simplificado de estimulação para crianças hospitalizadas na faixa etária de 0 a 12 meses, Enfermagem Modema, São Paulo, 3 (2): 24-33, 1985.

13 PERCY, A. Características do recém-nato e ajustamento faniliar In: Enfermagem Pediátrica, 9 ed., Rio de Janeiro, Interamericana, 1979. p. 116-28. 


\section{ROTEIRO DE ORIENTAÇÃO DAS MÃES PARA ESTIMULAÇÃO \\ DA CRIANÇA DE 0 - 1 MÊS}

\section{O QUE DEVE SER FEITO}

- Cuide do bebê procurando curvar-se perto dele para que ele veja seu rosto.

- Deixe o bebê dentro de um berço com aberturas laterias para que ele possa ver as pessoas e objetos do ambiente que o cerca.

- Mude a posição do bebê no berço ou na rede para que ele veja coisas diferentes.

- Pendure objetos simples e coloridos que se movimentem com o vento numa distância de 25 a $30 \mathrm{~cm}$ em relação ao rosto do bebê.

- Coloque desenhos coloridos nas paredes do quarto mudando os mesmos sempre que possível.

- Permita o reflexo de luz natural (sol) ou artificial nas paredes do quarto.

- Apresente novos sons e vozes confortantes à criança utilizando, por exemplo, rádio, toca-fita ou outros.

- Cante, brinque ou fale com o bebê suavemente, pegue-o com delicadeza quando estiver prestando algum cuidado.

- Converse normalmente no quarto ou sala onde o bebê esteja presente, evitando apenas barulhos desnecessários.

- Deixe o bebê ouvir outros sons como a televisāo, rádio ou o som da água caindo da torneira.

- Carregue o bebê bem junto do seu corpo pois ele gosta de sentir o cheiro e o calor do corpo humano.

- Deixe o bebê se movimentar livremente, evitando o uso de roupas ou cobertores apertados que dificultem seus movimentos.

- Use reoupas de acordo com a temperatura ambiente.

- Coloque o bebê bem junto do seu corpo quando for amamentar, de preferência esteja com a parte superior da roupa descida até à cintura.

- Dê banho no bebê esfregando e massageando todo o corpo dele ora com as mãos, ora com uma esponja para que ele possa sentir a diferença do contato.

\section{QUANDO DEVE SER FEITO}

Durante o banho, troca de fralda

Durante as horas em que o bebê estiver acordado.

\section{Diariamente}

Sempre

Sempre que possível e quando o bebê estiver acordado.

\section{Diariamente}

No banho, troca de fraldas, na hora da alimentação.

Nas horas que o bebê estiver acordado quando a famflia estiver reunida.

Fora dos horários de repouso e sono.

Sempre que estiver com ele no colo.

\section{Diariamente}

Sempre

$\mathrm{Na}$ amamentação nas cólicas do RN.

$\mathrm{Na}$ hora do banho. 
ANEXO 2

ESTIMULAÇÃo PRECOCE DA CRIANÇA PROGRAMA DE CO-EXECUÇÃo ENTRE A MĀE E A ENFERMAGEM

\section{MAMÃE}

VOCÊ ESTÁ COMEÇANDO A CONVIVER COM SEU PRIMEIRO FILHO. DO MESMO JEITO QUE ELE PRECISA DO SEU LEITE, ELE PRECISA TAMBEM DOS SEUS CUIDADOS E DO SEU CARINHO. SE VOCÊ DER ALIMENTO, AMOR E CUIDADOS, ELE TERÁ GRANDES CHANCES DE SER UMA CRIANÇA SADIA, ATIVA, CURIOSA E CARINHOSA.

VOCÊ QUER UM BEBÊ ASSIM?

SE QUER, NÓS VAMOS AJUDAR,, VISITANDO VOCÊS E ORIENTANDO.

AQUI ESTÃO ALGUMAS IDÉIAS PARA VOCE FAZER E AJUDAR SEU BEBÊ À CRESCER E VIVER SADIO.

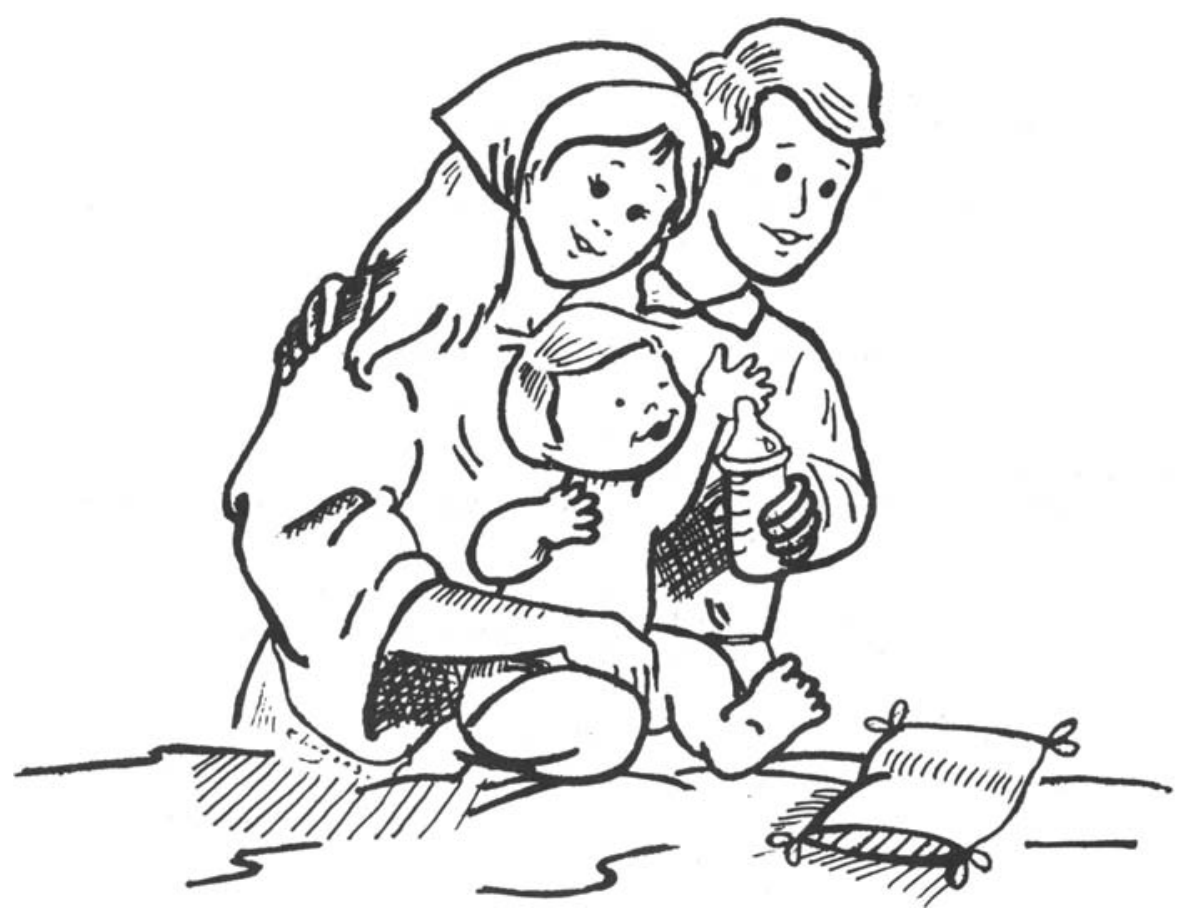

GUIA SIMPLIFICADO DE ORIENTAÇÃO - 0 A 1 MÊS 


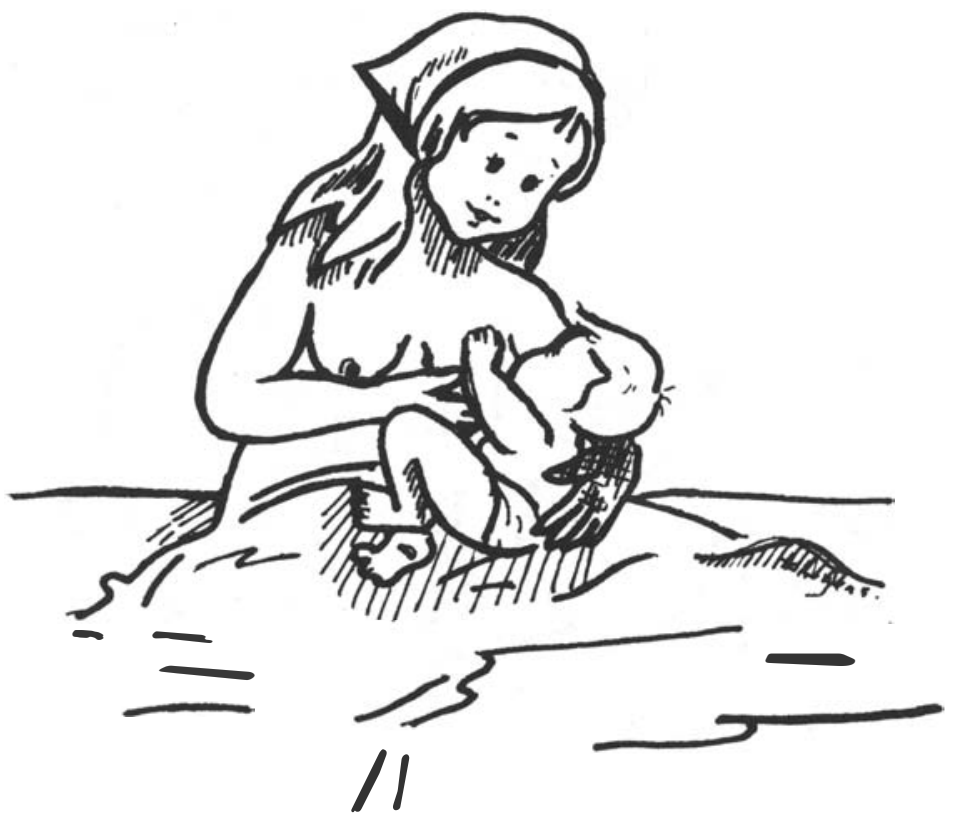

COLOQUE O BEBÊ BEM JUNTINHO DE VOCÊ QUANDO FOR AMAMENTAR, DE PREFERÊNCIA BAIXE SUA ROUPA ATÉ À CINTURA PARA ELE SENTIR MAIS SEU CALOR E SEU CHEIRO. 


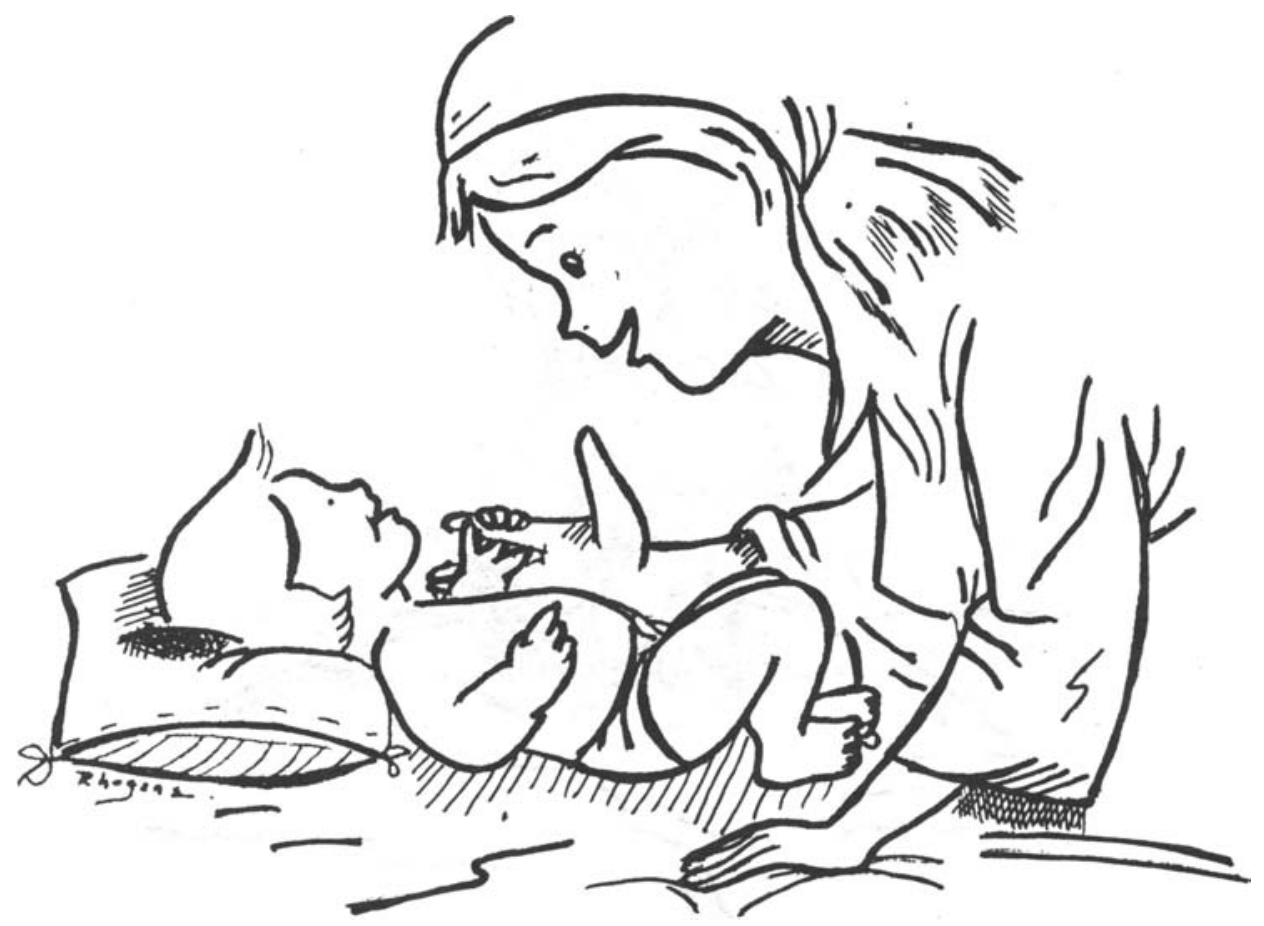

CONVERSE E CUIDE DO BEBÊ FICANDO BEM PERTO DELE. ASSIM, ELE PODE VER MELHOR O SEU ROSTO. 


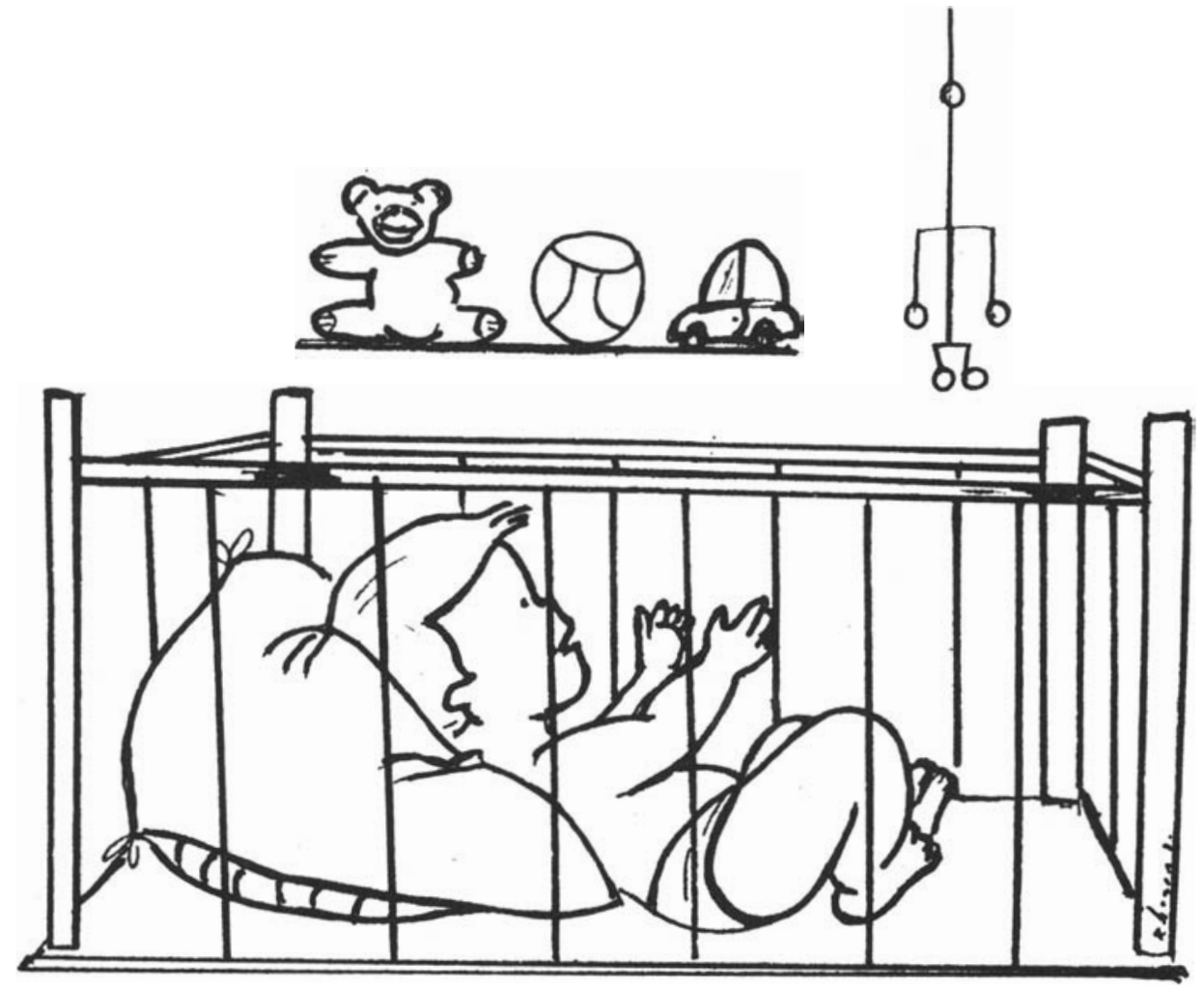

OS LADOS DO BERÇO DEVEM TER ABERTURAS QUE DEIXEM A CRIANÇA VER AS PESSOAS E OS OBJETOS QUE ESTÃO DO LADO DE FORA. 


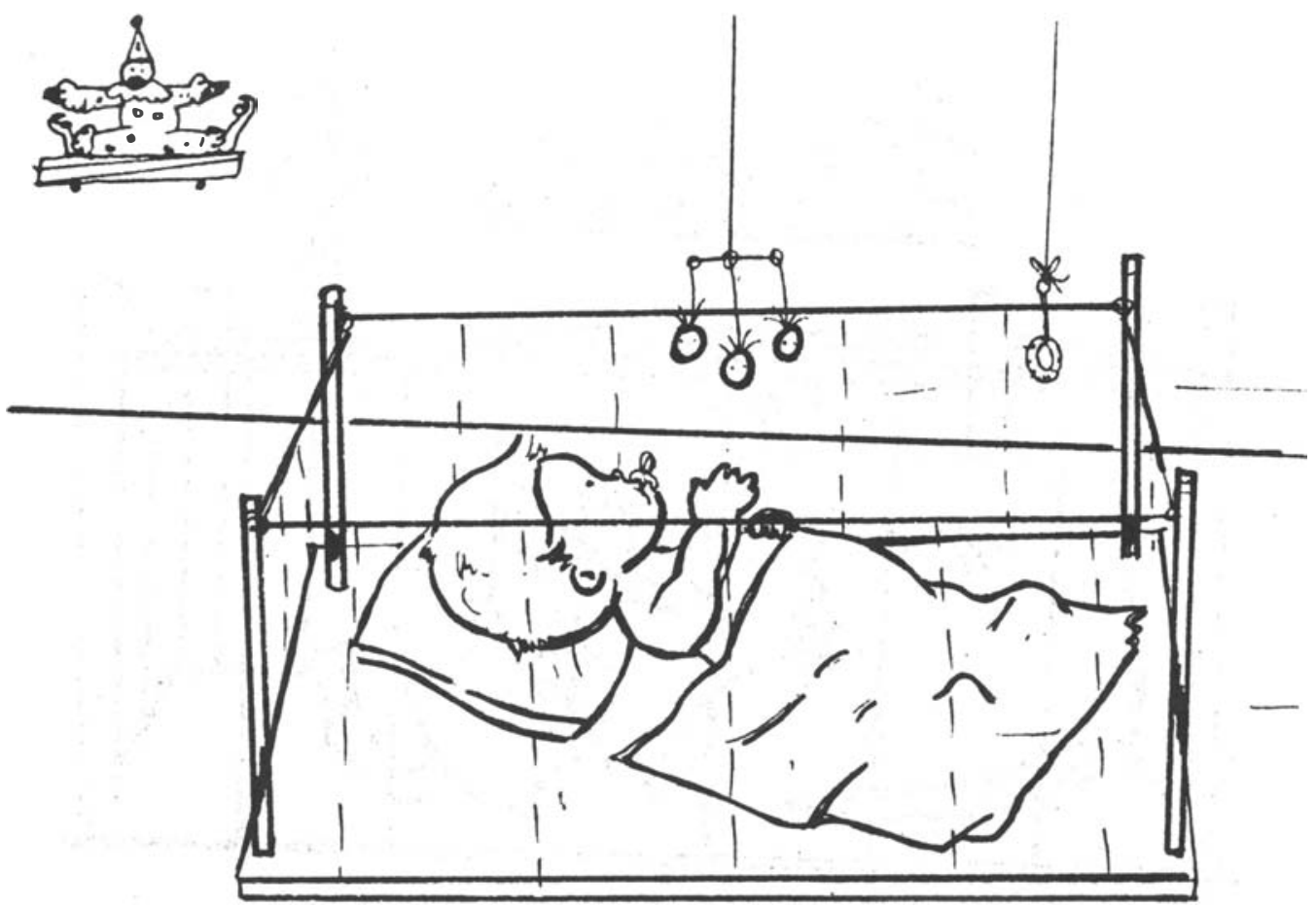

PENDURE BEM PERTO DO ROSTO E DAS MÃOS DO BEBÊ, OBJETOS LEVES, SIMPLES E COLORIDOS. 


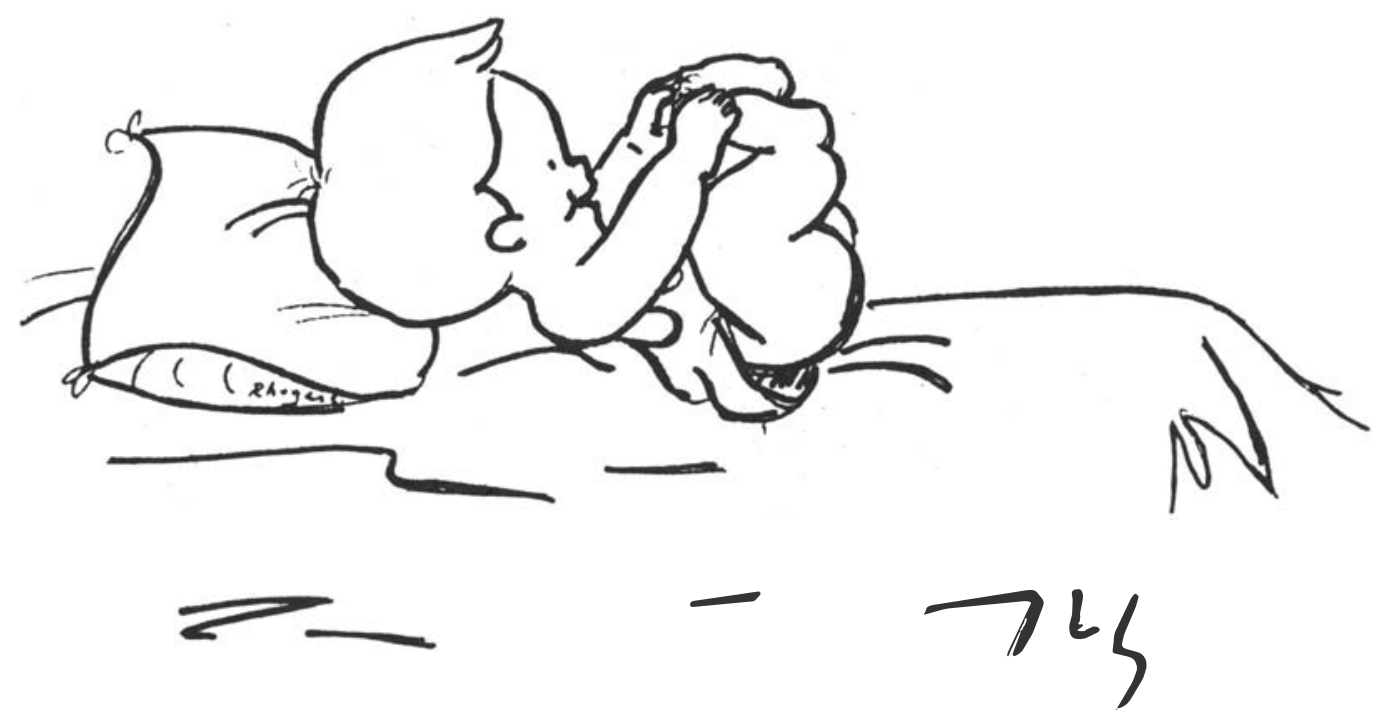

EVITE VESTIR O BEBÊ COM ROUPAS APERTADAS. COM ROUPAS FOLGADAS E DE ACORDO COM O CLIMA, ELE SE MOVIMENTA MELHOR E É MAIS CONFORTÁVEL. 

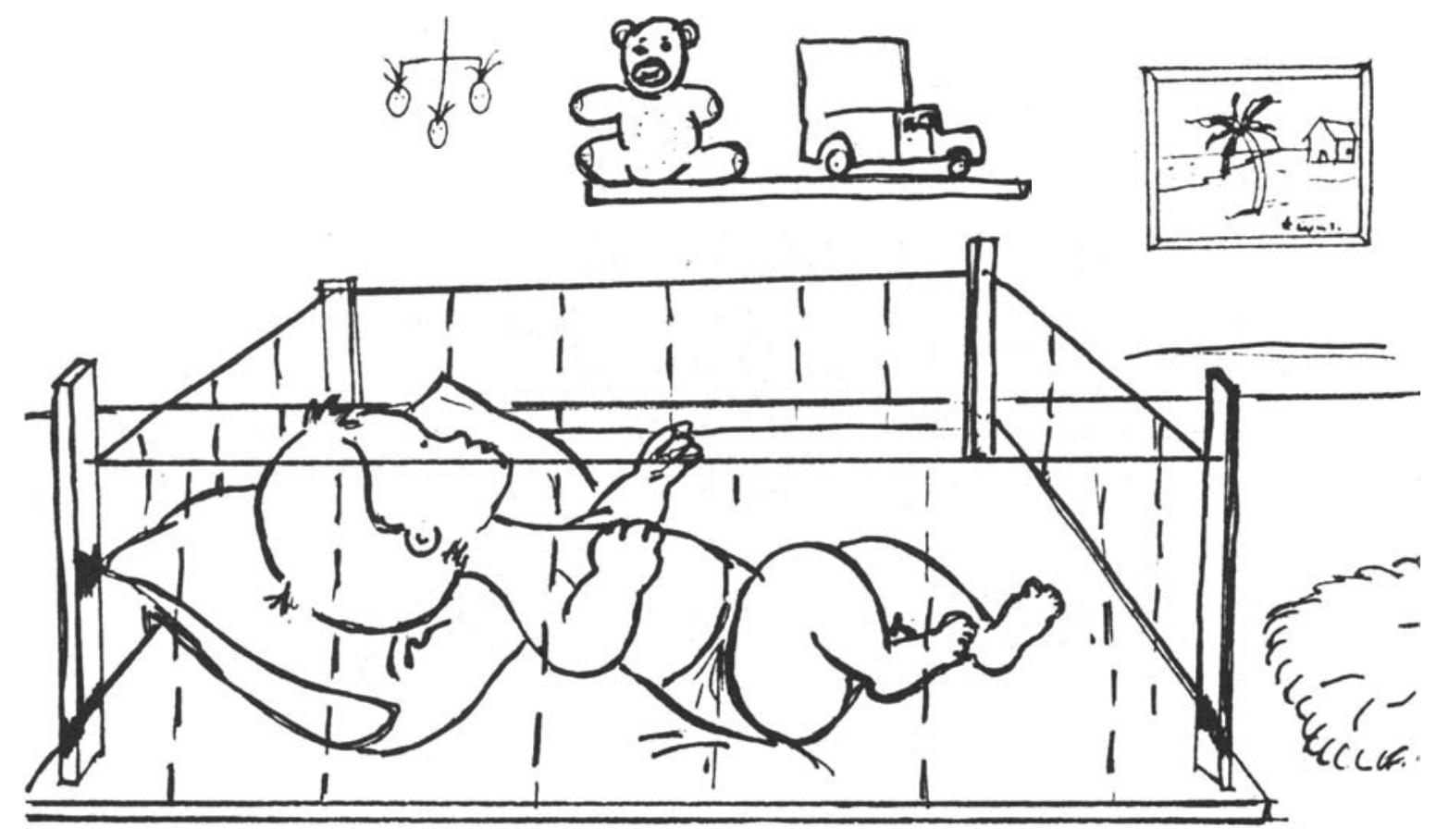

COLOQUE GRAVURAS E DESENHOS COLORIDOS NAS PAREDES. TROQUE OS DESENHOS COM FREQÜÊNCIA. 


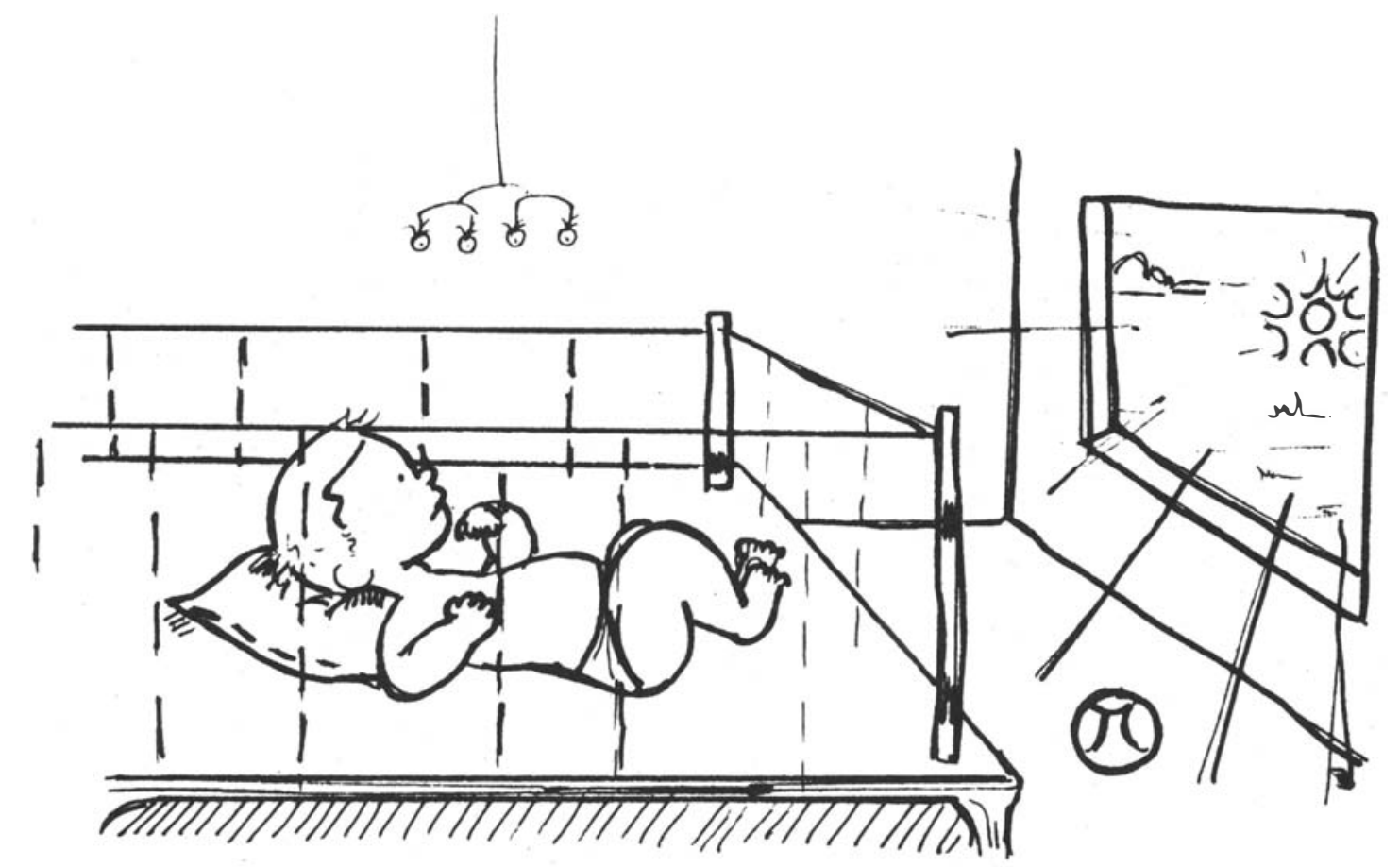

DEIXE ENTRAR UM POUCO DE SOL E DE VENTO NO QUARTO DO BEBÊ. ISSO FAZ BEM À SAÚDE. 


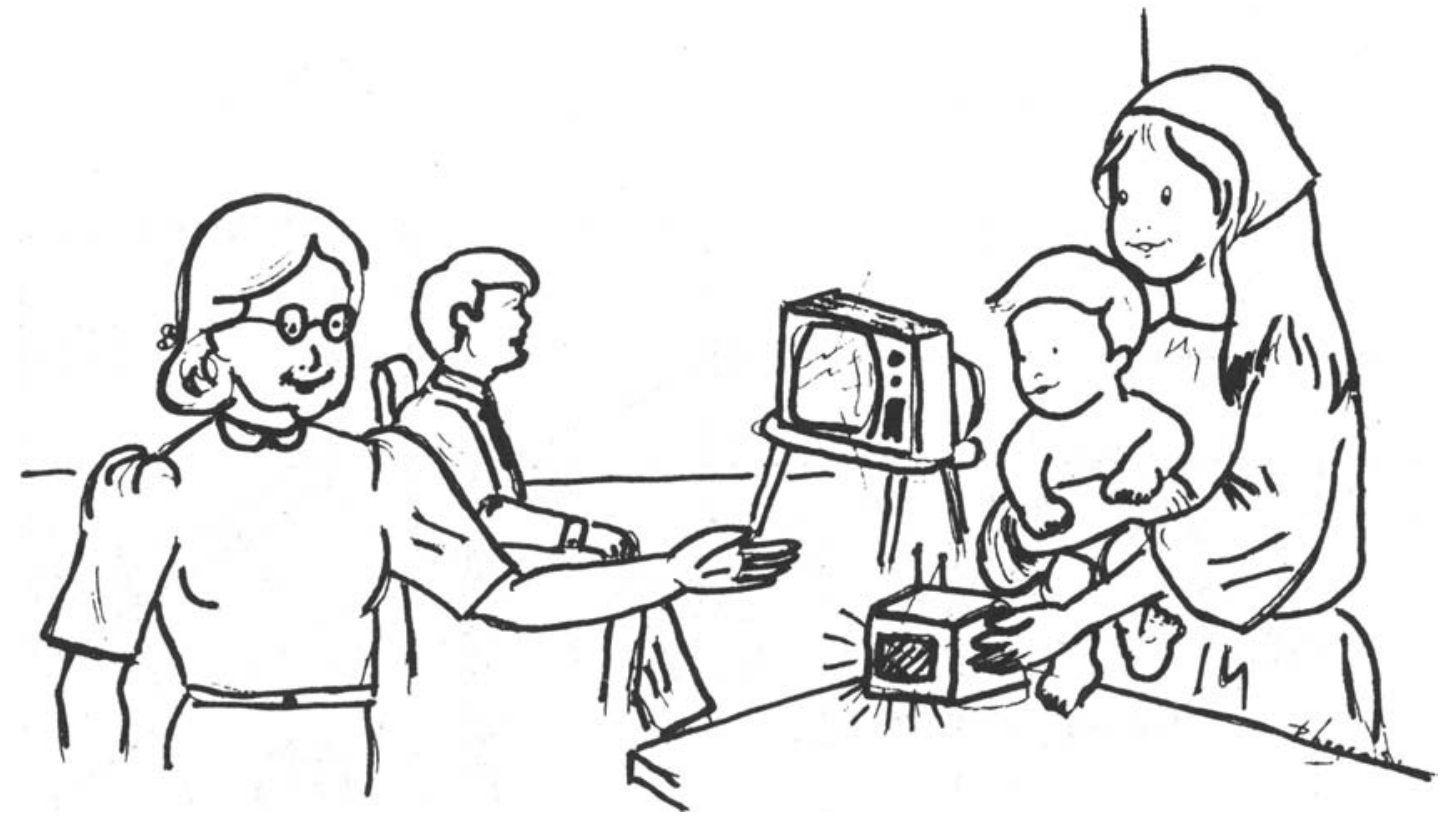

O BEBÊ DEVE ESCUTAR SONS AGRADÁVEIS E DIFERENTES COMO A VOZ DOS AVOS, PAIS, IRMÃOS, O RÁDIO, A TELEVISÃO. EVITE APENAS BARULHOS DESAGRADÁVEIS. 